\title{
Smart home automation towards the development of smart cities
}

\author{
Tanweer Alam, Abdulrahman A. Salem, Ahmad O. Alsharif, Abdulaziz M. Alhujaili \\ Department of Computer Science, Faculty of Computer and Information Systems, Islamic University of Madinah, \\ Saudi Arabia
}

\begin{tabular}{|c|c|}
\hline Article Info & ABSTRACT \\
\hline Article history: & The home automation system is indeed a system that offers a mobile \\
\hline Received Jan 12, 2019 & home appliances like light, fans, air conditions, and smart security locks, etc. \\
\hline Revised Dec 17, 2019 & Bluetooth or Wi-Fi is used for remote control of things. The smart home is \\
\hline Accepted Jan 4, 2020 & $\begin{array}{l}\text { essentially how it looks: automating with such an easy touch of a button or a } \\
\text { voice command the ability to manage things across the home. Several }\end{array}$ \\
\hline Keywords: & $\begin{array}{l}\text { operations were both simple and extremely low-cost, such as setting up a } \\
\text { light to turn on and off at the time of your moment. Others need much more }\end{array}$ \\
\hline Arduino & money and resources, including advanced spy cameras. Some people thought \\
\hline Internet of things & in a modern generation where smart and intelligent systems are necessary to \\
\hline Mobile apps & be there wherever we are to make our lives easier and much better, for \\
\hline Smart cities & example, we can do many things faster, better, and more accurate. \\
\hline
\end{tabular}

This is an open access article under the CC BY-SA license.

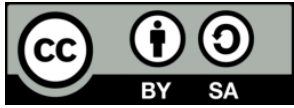

\section{Corresponding Author:}

Tanweer Alam,

Department of Computer Science,

Faculty of Computer and Information Systems,

Islamic University of Madinah, Saudi Arabia.

Email: tanweer03@iu.edu.sa

\section{INTRODUCTION}

Through the years when smart systems were the only topic that all people talking about, a group of some persons had an idea to improve the living style and taking modern technology into consideration [1]. They found out that it would be great if houses will have something similar to the way of human-like. For example, we might forget to turn the lights off [2], so, we will pay money for that and we will regret it at the end of the month, so they had somehow an idea of having a Home Automation Systems [3]. Home Automation Systems are applications that have the accessibility to the whole house's controls, such as, lights, TV, AC, garage, doors, and so on [4]. Home automation management systems have always future hints. Lights will turn on when entering the room, Fans will be activated when the temperature is too low, Allow the family members to enter the house throw security looks that can detect all of the family members [5]. Mostly, people will think this is unreachable, they will say it's impossible but actually, it is true! The way that people think is different from the way that we think as developers, they think it needs a lot of devices to control the entire house fields, but, it doesn't. All we need is one smart device to install the application that was programmed for a specific house and then you can run this app as you want. Home automation systems built to be structured as the user required, it is reachable [6].

Figure 1 shows the structure of the home automation system. Even though the system has the security part which is more I like, it can detect the family members using a scanned face by saving them in the database and recall that part while scanning, so it will immediately open the door when any member of 
the family is there. During the calculation of the percentage and of having a large amount of wasted electricity power in the last few years, and some other information that the current systems have. Our aim is to have the ability to let everyone live on his own lifestyle, erasing the fear of thieves and the shock after looking at the energy bill. No matter how hard we will work, no matter how much they want us to risk, our point is walking away after recognizing the perfect smile of those users we have. We would define the problem as follows:

1. The common property of success and the ability to make the house as less energy cost as possible such as having the safety power mood that will detect if there is no one inside a room for a couple of minutes it will immediately shut the power off.

2. The tragedies happened to houses by thieves at late nights especially when the owners are not there because their house doesn't provide any security systems.

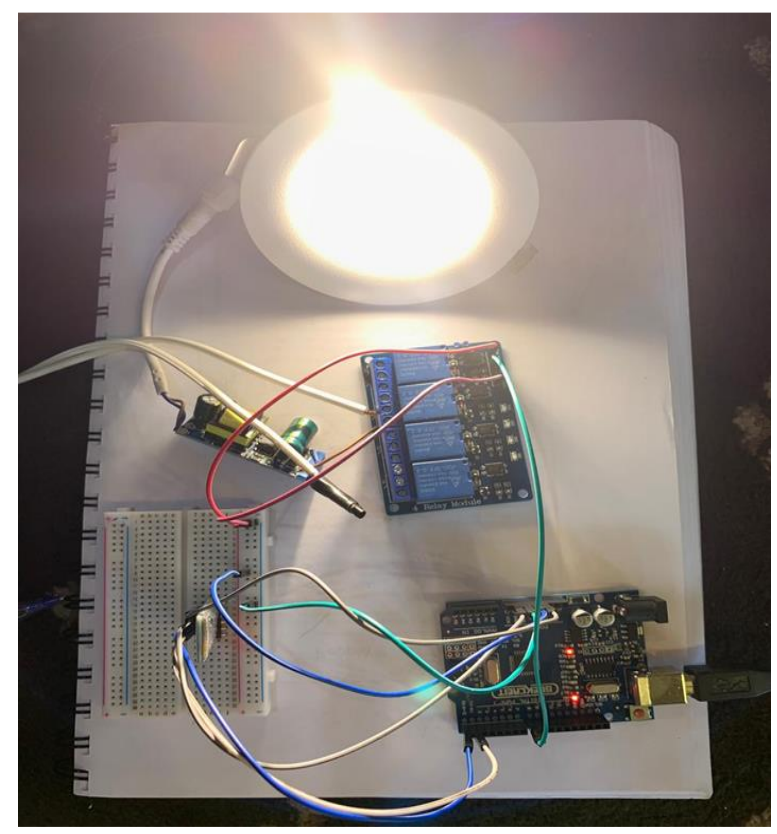

Figure 1. Home automation system block diagram

The blockchain technology is the novel approach to provide security of the data gathered from Bluetooth or wi-fi [7-8]. Now instead of turning all of these controls off by going to each button and switch them off, you can just use your smart device and switch whatever you want off, indeed, it will reduce the time you take to make sure about all of your house's area and check all of the controls. Our systems will also have less cost compared with any normal electricity powers in case of power safety. No matter how big is your house, the system is capable of more than you will ever imagine.

A questionnaire is a fast and effective method used to acquire information from a targeted group of people. By coming up with a few questions designed to get suggestions and the opinions of the application users, we were able to remove unnecessary functions and provide more suitable ones to implement in the application. 1) Have you ever heard about Home Automation System? - they say it's a technology that could be really helpful in the future. 2) Have you ever used the Home Automation System? - we have the answers as expected, it's mostly never used it before and this will lead us to our goal which is letting everyone using the system easily and comfortably. 3) What would you prefer? - using the system as a smart device application easier for most of the users because they can open the system faster and use it. 4) Do you think it's a good idea? - yes, it's a good idea because the said they are having a problem with the electricity cost during the month. 5) Do you think it's useful? - yes, also because the users always facing the same problem for the huge cost of electric power. 6) Do you think it will be easy to use? - yes, we are living in a modern century that everyone can use smart devices so easily and they are familiar with this kind of technology.

The rest of the paper is organized as follows: Section II represents the literature review, section III represents the components of the system, section IV shows the methodologies for software development, section V represents the survey results and discussion and section VI shows the conclusion. 


\section{LITERATURE REVIEW}

The Internet of Things (IoT) during the last few years was used so widely in the smart house systems [9-10]. By controlling almost all appliances and security. The system consists of Arduino Uno Board, PIR sensor, temperature sensor, gas sensor, power select, and web applications. GSM is used to communicate the microcontroller and the web page and facilitates energy management. It also monitors the type of device encountered at home and activates the operations. The sensor parameters will be stored in the cloud. The system also can be used in mobile health care, traffic management, and so others. In the $21 \mathrm{st}$ century, there was a man that had an idea which allowed him to access all the devices. Now we can even access the internet with only one click. Home automation is a mobile application for the safety and proper use of a human. In the last 10 or more years ago, we used to switch the home appliances manually. Based on the difficult access. At the beginning of this new automation, it was not considered an effective method yet. As technology has improved this system to control by Bluetooth modules. The problem with using Bluetooth is that it has a limit of the wireless range, also a chance of interference with other devices using Bluetooth. In advance, they made this kind of automation to be used using Android by android mobile phones [11]. Lately, they figured out a system that can control and monitor the home appliances using any device which has an internet connection.

In the last years, home automation has achieved a really great job and increased the comfy of a lifestyle. Smartphones are used to control all of their home appliances. You can communicate with all the home's controls using a smart device including new techniques. We never forget how the home automation has extremely grown, these systems have been created to improve the comfortability of a lifestyle especially for those who are elderly and disabled these systems are designed by using a single controller that owns the ability control interconnected appliances such as lights, TVs, and so on. The most interesting thing is that you can control all of these appliances easily by using smartphones. Home automation systems could be controlled throw some methodologies such as Bluetooth and Wi-Fi. Bluetooth is a technique that is secured and low cost as well. The hardware will be using an Arduino BT board and cell phone is wirelessly using Bluetooth. The smartphone uses the application that allows the user to control these appliances. The system also uses passwords to make sure it's not going to be used by some others. The home automation system structural diagram is shown in Figure 2.

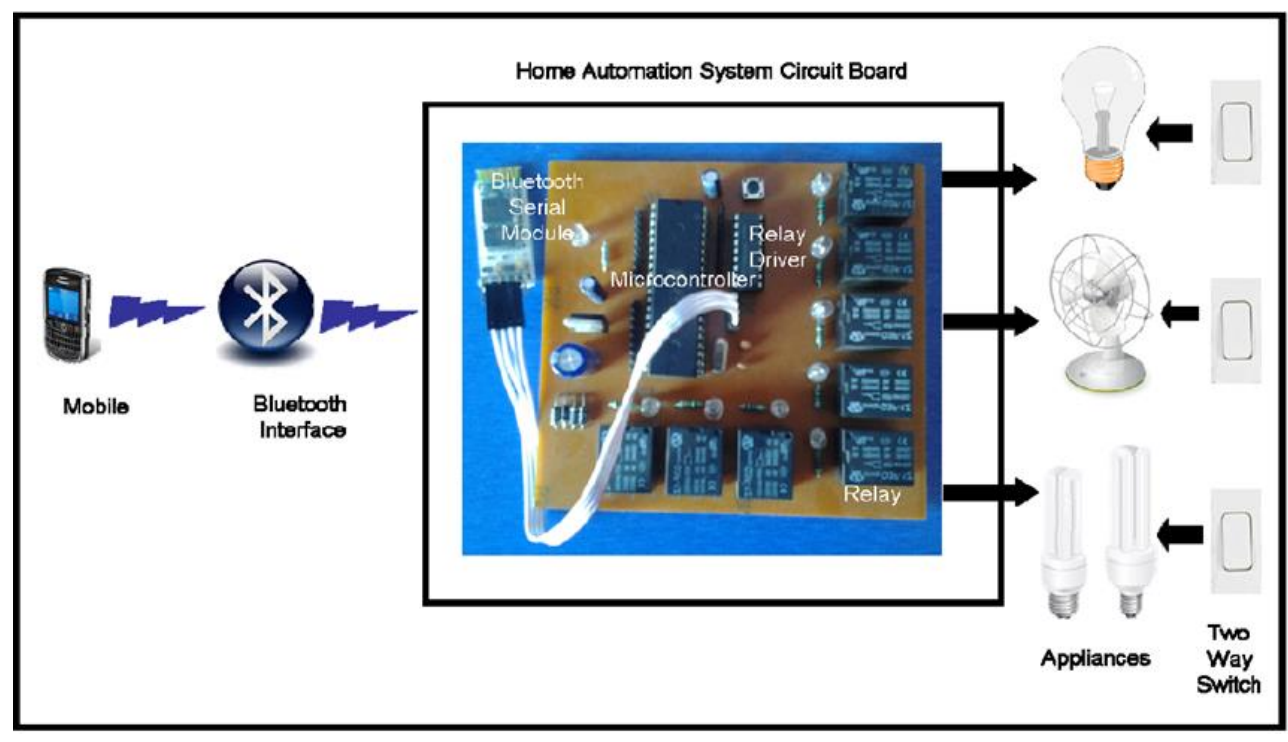

Figure 2. Home automation system structural diagram

Voice recognition also implemented by a researcher. Android OS has a built-in voice recognizing feature ability to control the home appliances from user voice commands [12]. The application converts the voice into a text after that it sends that message to the Bluetooth module that is connected to the Arduino. The great thing of this voice application transmit is that the user only needs to pronounce the application name throw the microphone and say the commands that he wanted to do such as turn the light ON or OFF. By using this kind of home control, the user doesn't have to do anything except saying the words that the application will recognize to achieve these commands. 
In this research, they've explained how the home automation system works. this system works in smart devices using the android application and gives the user some services to make this technology easy for controlling the house. These services are connected and used by connecting the smart devices via Bluetooth technology but it can handle only 24 devises at most at the same time with more than $100 \mathrm{~m}$ range of Bluetooth signals. but the problem in this research is that the signal has a limited range to be controlled and it will not work with a big distance, also, it's not supported by Wi-Fi.

\section{SMART HOME AUTOMATION SYSTEM COMPONENTS}

The following are the main components of the smart home automation system.

- User interface

- Smart device

- Arduino

- Android application-based Wi-Fi

The home automation systems will provide the need and the user requirements to handle all of these problems and tragedies that could happen in life [13]. Sometimes we can do something to handle these problems. But, sometimes we're so far away from home. Therefore, the best way to think about while you have this situation is by using these modern systems, and it will be as follow:

- The system will reduce power consumption.

- The system will also reduce manual power.

- The system will work efficiently and effectively.

- The system will work in real-life time.

- The system is a real challenge for people.

- The system has also powerful security.

- The system will also include scanning cameras to support both cases which are recognizing the family members and recording any sense of the presence of other people who are rounding the house

In order to fill the gap of wasting the power of electricity in the houses, we have the idea of saving this cost of electricity which has been a problem in the last few years. Also, the security needed, especially when the owners are far away from home in case of traveling or other reasons. Two main objectives will be covered along with this project:

- Building an application to control the houses' appliances.

- Based on Wi-Fi connecting the house with the application.

The Functional Requirements are summarized as follows.

- Ability to process data according to user choice.

- Ability to apply the user commands immediately.

- Ability to switch on and off the power.

- Ability to recognize family members.

- Ability to access Arduino using a smartphone.

The nonfunctional requirement is as follows.

- Accuracy.

- High security.

\section{METHODOLOGIES}

In this research, we use waterfall model, "It defines some basic tasks, which are carried out in sequence requirements definition, architecture design, detailed design, implementation, component verification, integration verification, and requirements validation. Each task results in documents or other artifacts that are used as specifications for the next task, e.g. the detailed design specification forms the basis for implementation task. In the "ideal" form, one task should be completed before the next starts. There are however variants with overlapping tasks, and these are probably used more in reality. Implementation starts when some of the detailed design is ready, component tests when components are implemented. The following tools are used in the development of the system.

- circuito.io: is a software that uses to design the block diagrams and electronic circuits.

- Tinkercad: It is a software that uses to design the hardware.

- draw.io: It is used to design UML diagrams.

- Erdplus: is used to design an entity-relationship diagram.

- Justinmind: is a software tool uses to make and build the interface. 
Arduino software 1.8.9 - this software is used for the implementation of the application in the coding part.

Bluetooth Automation - this application is used to connect the Arduino with the appliances as the connection part between the user and the system.

The system should focus on helping the management/admin of the system:

For the management the system should have:

- $\quad$ Adding, uploading and deleting.

- Prevent unauthorized access.

- $\quad$ Monitor all the appliances distributed around the house.

\section{RESULTS AND DISCUSSION}

The following interfaces are included in the system.

a. Organization admin: admin should have training on the system to be able to access the data.

b. General admin: the ability to give help to the user admin and also give permission to the user to access all the covered appliances in the house.

c. User connection: ability to have the choice of using Bluetooth or Wi-Fi.

d. Controllability: the ability to control all the house appliances.

The following hardware is required to develop the home automation system.

a. Smart Device: tablets or any smart device.

b. Connection: Which can be supported by Bluetooth or Wi-Fi.

c. Arduino Uno board: to connect the appliances with the system.

d. The Following Software required

e. Android studio: to create the interfaces, and implementation of the program.

f. Operating system: Android.

g. Arduino software: upload the codes into the Arduino board.

h. Database: SQL server management studio to creating the database.

Unified Modeling Language (UML) "Provide the development community with a stable and common design language that could be used to develop and build computer applications" (bell.2003) in this report, we use three types of UML models, which are:

- Use case diagram: "A use case illustrates a unit of functionality provided by the system the main purpose of the use-case diagram is to help development teams visualize the functional requirements of a system, including the relationship of "actors" (human beings who will interact with the system) to essential processes, as well as the relationships among different use cases like as shown in Figure 3 and Figure 4.

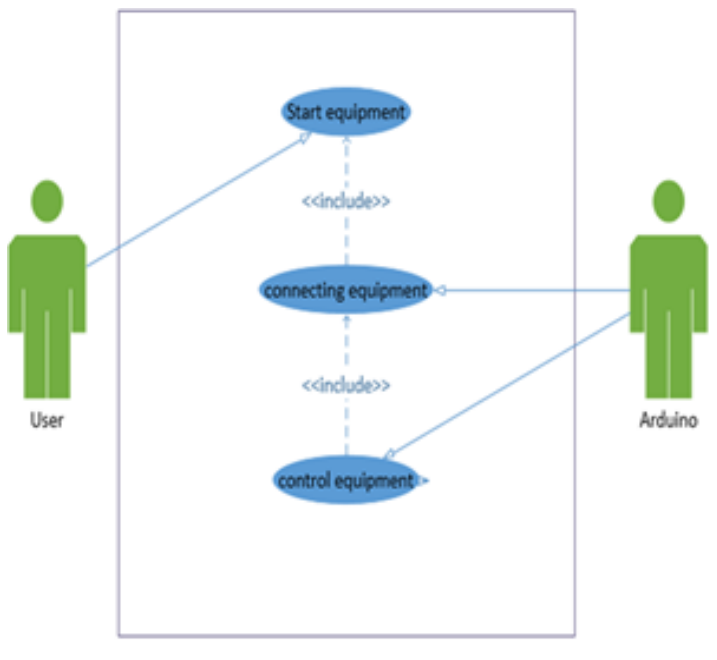

Figure 3. Use case diagram between user and hardware

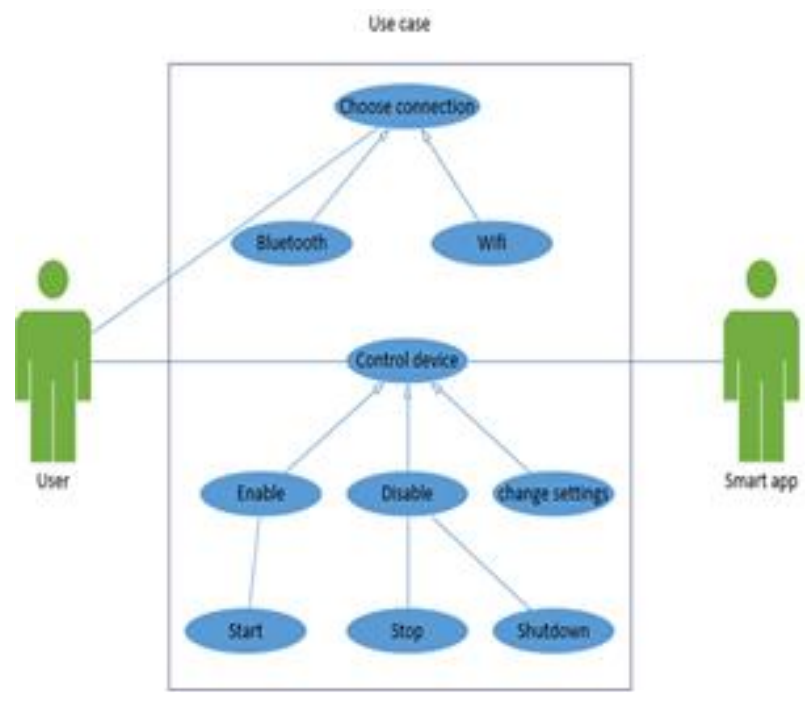

Figure 4. Use case diagram between user and smart app 
- Activity diagram: "Activity diagrams show the procedural flow of control between two or more class objects while processing an activity like as shown in Figure 5.

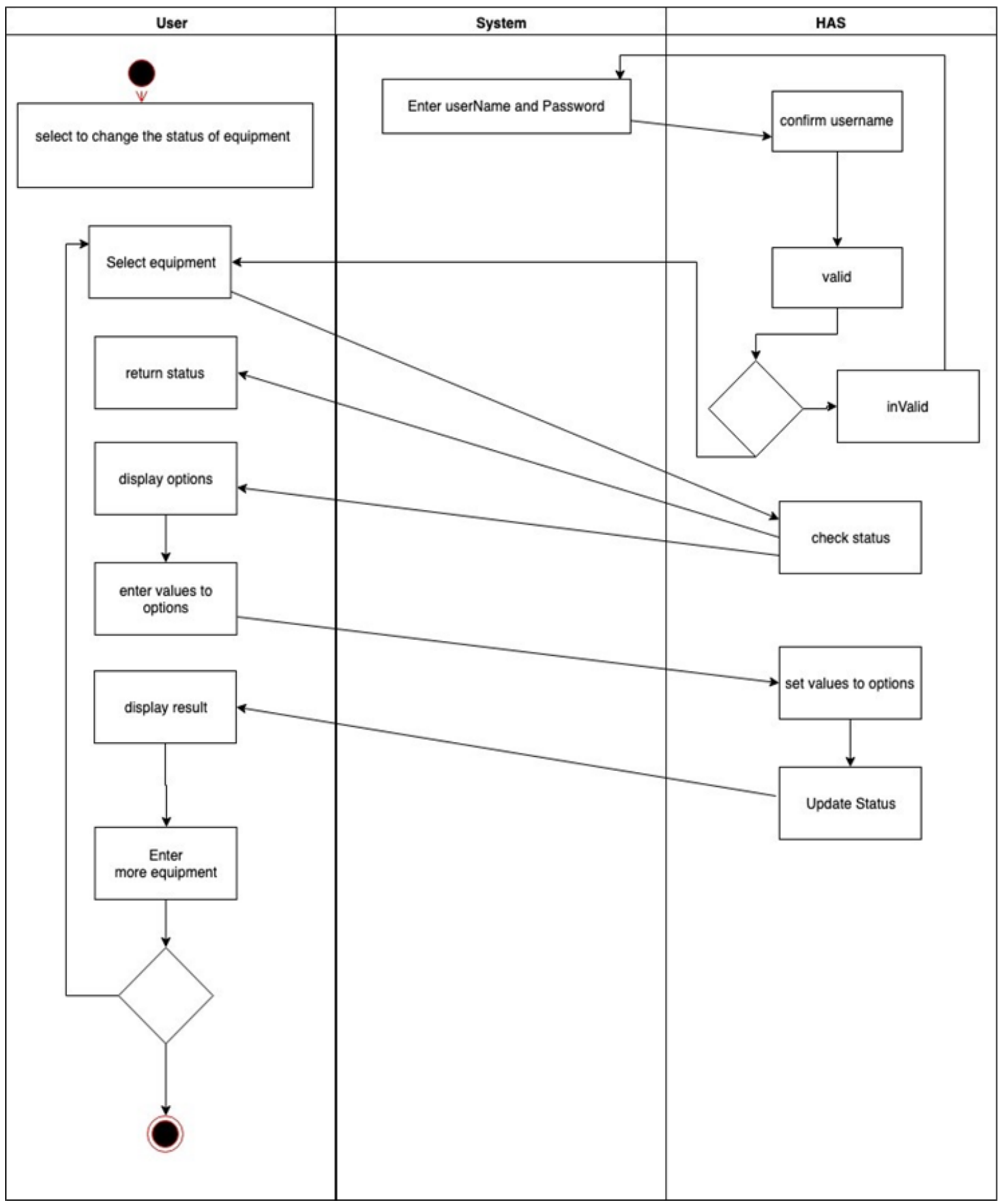

Figure 5. Activity diagram of the system

- Entity Relationships Diagram: "is used for describing data and the relationship between different entities in a database. It creates a visual map outlining process requirements and detailing connections among entities and their attributes.

- $\quad$ Block Diagram: a high-level diagram used in engineering too. It's also used to create new systems or improving an existing system. The Interfaces of smart app can be seen in Figure 6. 
Our system has made to help the oldest and disabled people. It can be used by many users as it shows in the report. The system is created to do whatever the user wants for controlling the house's equipment using a smart device that can be supported by our programming language.

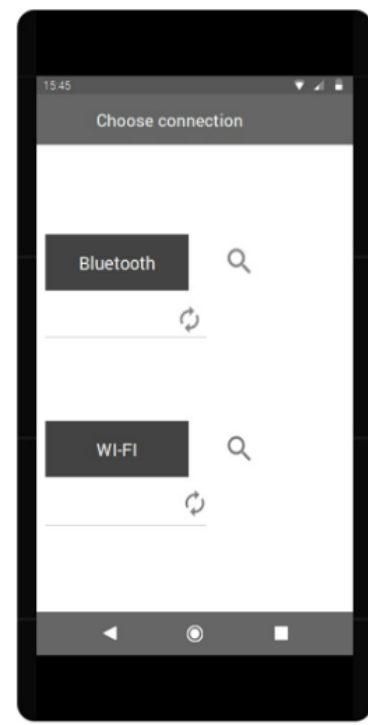

(a)

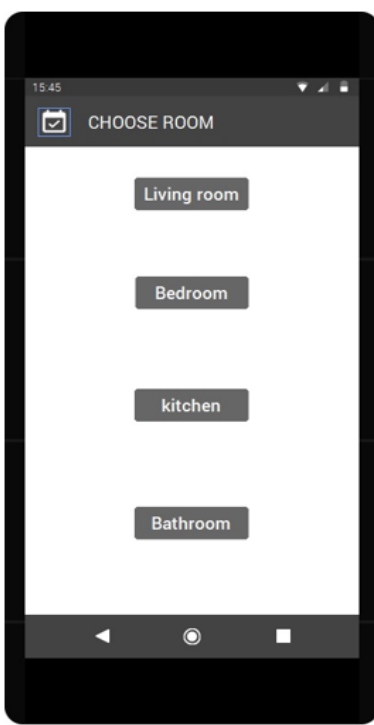

(b)

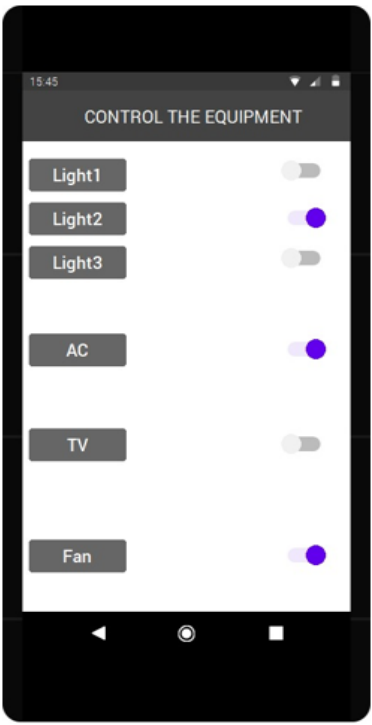

(c)

Figure 6. Interfaces of smart app

\section{DISCUSSION}

A survey was publicly opened in the area of Madinah city. Peoples were interested a lot in this system. As a result of the following survey questions is mentioned in Figure 7.

- Que (1) Have you ever heard about Home Automation System?

- Ans1- they say it's a technology that could be really helpful in the future.

- Que (2) Have you ever used the Home Automation System?

- Ans2- we have the answers as expected, it's mostly never used it before, and this will lead us to our goal which is letting everyone using the system easily and comfortably.

- Que (3) What would you prefer?

- Ans3- using the system as a smart device application easier for most of the users because they can open the system faster and use it.

- Que (4) Do you think it's a good idea?

- $\quad$ Ans 4- yes, it's a good idea because they said they are having a problem with the electricity cost during the month.

- Que (5) Do you think it's useful?

- $\quad$ Ans 5- yes, also because the users always facing the same problem for the huge cost of electric power.

- $\quad$ Que (6) Do you think it will be easy to use?

- Ans6- yes, we are living in a modern century that everyone can use smart devices so easily and they are familiar with this kind of technology.

The charts in Figure 7 will be showing the percentage of the people that have been giving the answers for the survey. The system is implemented as a mobile application using Android technology shown in Figure 8. We consider Madinah as a use-case city. It is working nicely. It might be a key in developing the smart cities. 
Q1.

Have you ever heard about Home Automation System
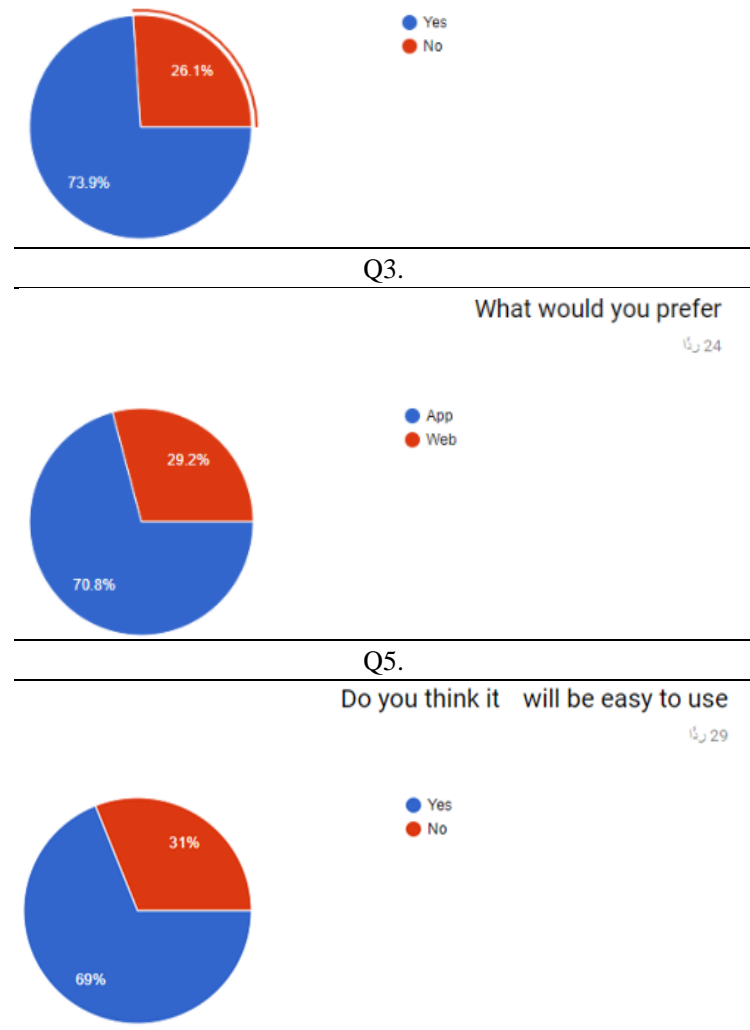

$\mathrm{Q} 2$.

Have you ever used the Home Automation System
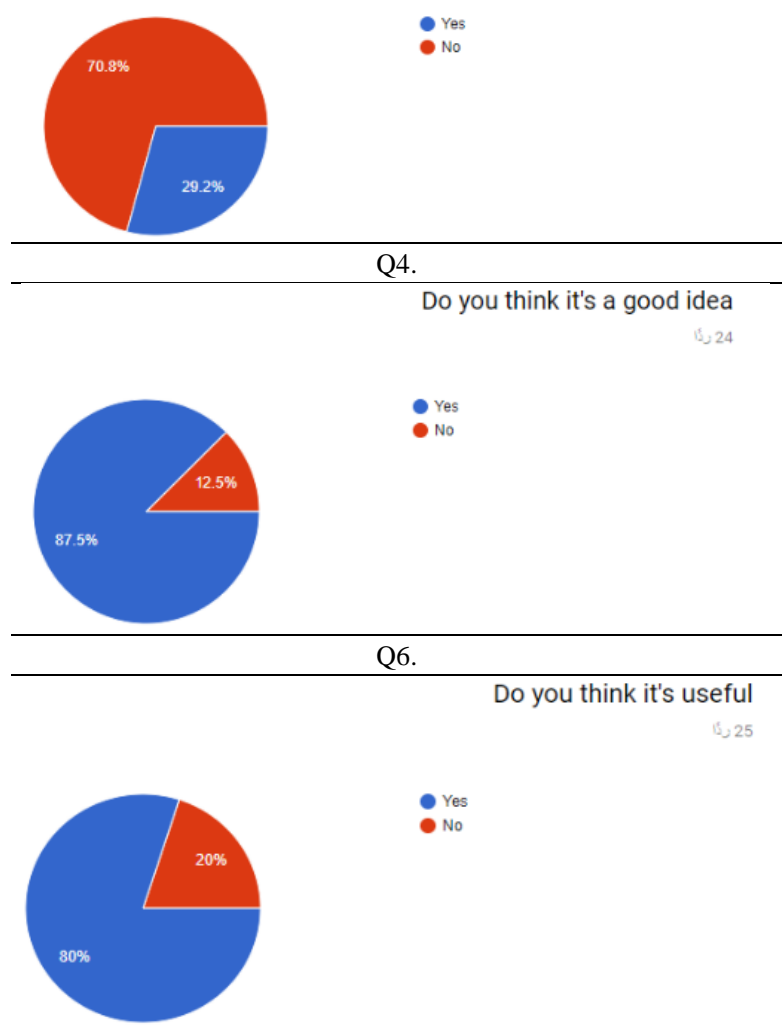

Figure 7. Survey results

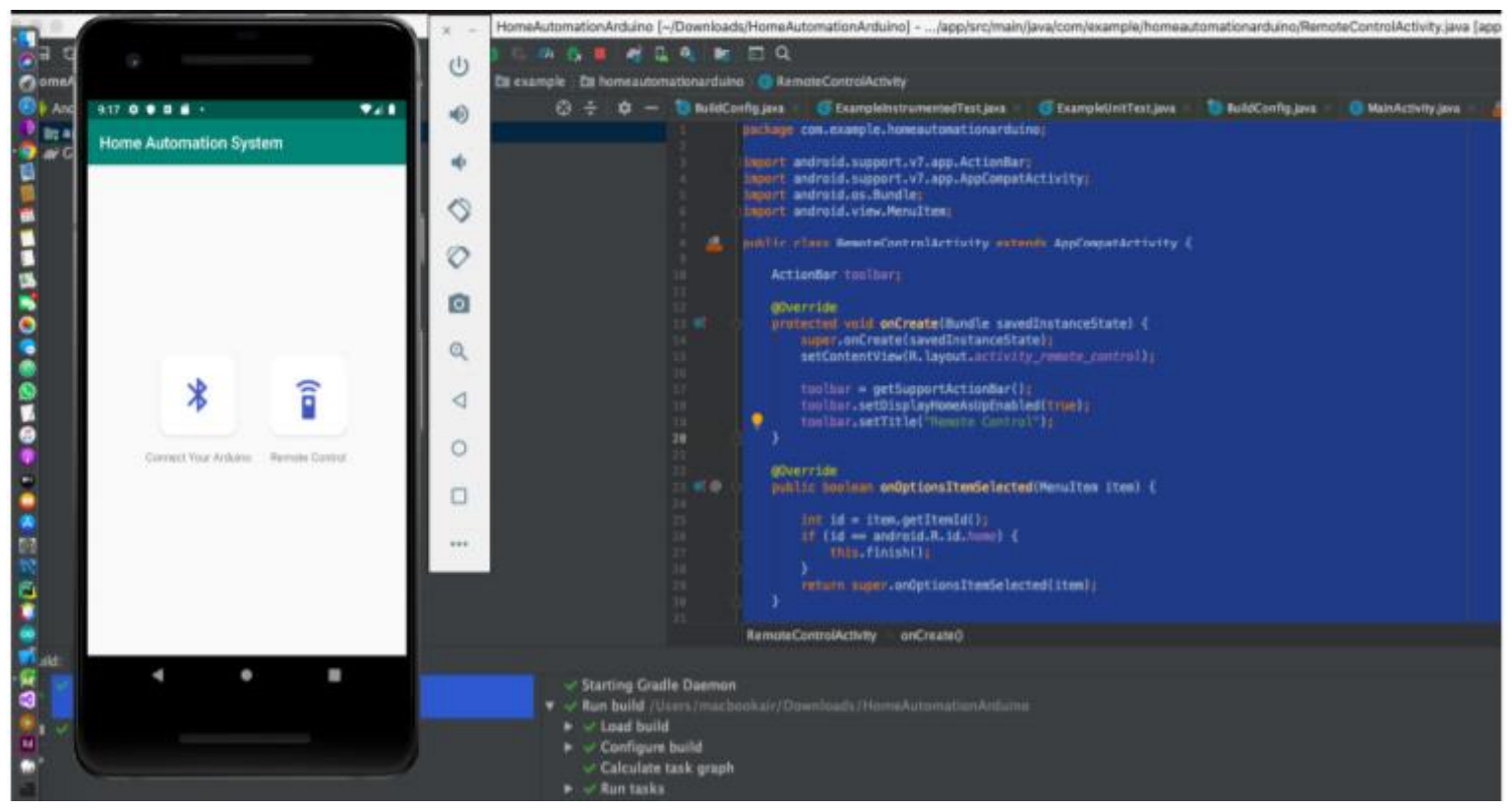

Figure 8. Implementation 


\section{CONCLUSION}

Smart systems are a designation that is given to the people which make their lives easier to improve the quality and execution, this research aims to provide a new hybrid solution for smart houses that is combine mobile application and an Arduino, because Smart houses are always focusing on leveling up the usability security as well, with the use of this solution for giving people the chance to control their own houses it will be a helpful method to achieve the goal of our system. as we mentioned before our system will give the chance to the user to choose either Bluetooth or Wi-Fi in this report our system will work only on Bluetooth we will be working on the next project for combining the Bluetooth and Wi-Fi together in the same application as the user wishes. Also, our full application system will be ready in the next report as a full version and we will cover more details about our methods and implementation of our system.

\section{REFERENCES}

[1] Alam T, Benaida M. "The Role of Cloud-MANET Framework in the Internet of Things (IoT)", International Journal of Online Engineering (iJOE). Vol. 14(12), pp. 97-111. DOI: https://doi.org/10.3991/ijoe.v14i12.8338.

[2] Tejani, Dhiren, Ali Mohammed AH Al-Kuwari, and Vidyasagar Potdar. "Energy conservation in a smart home." In 2011 5th IEEE International Conference on Digital Ecosystems and Technologies, pp. 241-246. IEEE, 2011.

[3] Alam, Tanweer. "Middleware Implementation in Cloud-MANET Mobility Model for Internet of Smart Devices", International Journal of Computer Science and Network Security, 17(5), 2017. pp. 86-94.

[4] Ehsani, Farzad, Silke Maren Witt-Ehsani, and Walter Rolandi. "Smart home automation systems and methods." U.S. Patent 9,230,560, issued January 5, 2016.

[5] Alam T, Benaida M. CICS: Cloud-Internet Communication Security Framework for the Internet of Smart Devices. International Journal of Interactive Mobile Technologies (iJIM). 2018 Nov 1;12(6):74-84. DOI: https://doi.org/10.3991/ijim.v12i6.6776.

[6] Tanweer Alam, Baha Rababah, "Convergence of MANET in Communication among Smart Devices in IoT", International Journal of Wireless and Microwave Technologies(IJWMT), Vol.9, No.2, pp. 1-10, 2019. DOI: 10.5815/ijwmt.2019.02.01.

[7] Tanweer Alam, "IoT-Fog: A Communication Framework using Blockchain in the Internet of Things", International Journal of Recent Technology and Engineering (IJRTE), Volume-7, Issue-6, 2019.

[8] Tanweer Alam, "Blockchain and its Role in the Internet of Things (IoT)", International Journal of Scientific Research in Computer Science, Engineering and Information Technology, vol. 5(1), pp. 151-157, 2019. DOI: https://doi.org/10.32628/CSEIT195137.

[9] Alam, Tanweer. (2018) "A reliable framework for communication in internet of smart devices using IEEE 802.15.4." ARPN Journal of Engineering and Applied Sciences. 13(10), 3378-3387.

[10] Tanweer Alam, "A Reliable Communication Framework and Its Use in Internet of Things (IoT)", International Journal of Scientific Research in Computer Science, Engineering and Information Technology (IJSRCSEIT), Volume 3, Issue 5, pp.450-456, May-June.2018 URL: http://ijsrcseit.com/CSEIT1835111.

[11] David, Nathan, Abafor Chima, Aronu Ugochukwu, and Edoga Obinna. "Design of a home automation system using arduino." International Journal of Scientific \& Engineering Research 6, no. 6 (2015): 795-801.

[12] Abidi, M. Ebrahim, Ani Liza Asnawi, N. FM Azmin, A. Z. Jusoh, S. Noorjannah Ibrahim, Huda Adibah Mohd Ramli, and Norun Abdul Malek. "Development of Voice Control and Home Security for Smart Home Automation." In 2018 7th International Conference on Computer and Communication Engineering (ICCCE), pp. 1-6. IEEE, 2018.

[13] Gunge, Vaishnavi S., and Pratibha S. Yalagi. "Smart home automation: a literature review." International Journal of Computer Applications. 975 (2016): 8887. 